\title{
Intractable chronic inflammatory demyelinating polyneuropathy treated successfully with ciclosporin
}

\author{
M Odaka, M Tatsumoto, K Susuki, K Hirata, N Yuki
}

See end of article for

J Neurol Neurosurg Psychiatry 2005;76:1115-1120. doi: 10.1136/jnnp.2003.035428

authors' affiliations

Jeurol Neurosurg Psychiatry 2005:76:1115-1120. doi: 10.1136/innp.2003.035428

Correspondence to:

M Odaka, Department of

Neurology, Dokkyo

University School of

Medicine, Kitakobayashi

880, Mibu, Shimotsuga,

Tochigi 321-0293, Japan;

m-odaka@dokkyomed.

ac.jp

Received

29 December 2003

Revised version received

16 November 2004

Accepted

18 November 2004

\begin{abstract}
Background: Chronic inflammatory demyelinating polyneuropathy (CIDP) is a heterogeneous disorder and both clinical course and response to treatment vary widely. Because of the propensity for relapse, CIDP requires maintenance therapy after the initial response to treatment. There is no consensus regarding this in the published literature.

Present report: A patient with CIDP was treated with oral prednisolone and cyclophosphamide pulse therapy but required repeated plasma exchange and intravenous immunoglobulin (IVlg). Treatment with ciclosporin freed the patient from repeated IVIg administration. Therapeutic responses in 14 subsequent cases including three patients who showed improvement with ciclosporin are also presented along with an algorithm of the authors' suggested protocol for treatment.

Conclusion: Ciclosporin should be considered for patients with intractable CIDP who require repeated IVlg.
\end{abstract}

C hronic inflammatory demyelinating polyneuropathy (CIDP) is characterised by hyporeflexia or areflexia and progressive or relapsing motor and/or sensory dysfunction of more than one limb, developing over at least two months. ${ }^{1}$ Randomised controlled trials have shown beneficial short term responses to steroids, ${ }^{2}$ plasma exchange (PE), ${ }^{3}$ and intravenous immunoglobulin (IVIg), ${ }^{5-8}$ but there is little information available on the effects of long term therapy. Therapy for CIDP should be individualised based on cost, availability, and potential adverse effects. IVIg and PE are expensive therapies, and protracted use of steroids is accompanied by a variety of side effects.

Ciclosporin is an immunosuppressive agent widely used in organ transplantation and certain autoimmune diseases. Reports suggest that it is effective for patients with CIDP who have experienced relapse or have failed to respond to other treatments. ${ }^{9-11}$ Here we report a patient with pure motor CIDP who showed no improvement with prednisolone and cyclophosphamide pulse therapy but was successfully and safely treated with ciclosporin. Therapeutic responses of and outcomes for 14 subsequent patients are also presented. The aim of our study was to develop a provisional treatment strategy for CIDP based on published clinical trials and our own clinical experience.

\section{CASE REPORT}

A 34 year old man developed weakness in his left arm in February 1998. One month later, he had weakness in his right arm. The symptoms gradually worsened and in May 1998 he could no longer walk without support because he was easily fatigued. Cranial nerve examination revealed no abnormalities. On the Medical Research Council scale, muscle strength was grade 3 for the proximal and grade 2 for the distal muscles of the upper limbs. In the lower limbs, muscle strength was grade 4 for both the proximal and distal muscles. There were no tendon jerks or glove and stocking type paresthesias. His sense of touch, pain, vibration, and position was normal. The neuropathy impairment score
(NIS) (previously called the neurological disability score ${ }^{2}$ ) for the right side was 48 and for the left side 51. (Based on the report by Dyck et $a l^{2}$ the NIS was evaluated by sum score of the impairment of cranial nerves, muscle weakness, reflexes, and sensation: $0=$ deficit, $1=$ mild deficit, $2=$ moderate deficit, $3=$ severe deficit, and $4=$ complete absence of function or severe deficit. Total score for maximum severity $=120$.)

The results of the nerve conduction study are shown in table 1. In accordance with the diagnostic criteria for CIDP, ${ }^{1}$ both the median and ulnar nerves had decreased motor conduction velocity. The left peroneal nerve had a partial conduction block. Abnormal temporal dispersions were noted in the segments between the wrist and elbow for both ulnar nerves and between the ankle and the segment below the fibular head for the right peroneal nerve. Both the median and posterior tibial nerves had prolonged distal latencies, and in the median and posterior tibial nerves the minimal $\mathrm{F}$ wave latencies were prolonged. Sensory nerve conduction studies showed no abnormalities. These findings met the demyelination criteria for CIDP. ${ }^{1}$

On cerebrospinal fluid examination the protein level was raised $(99 \mathrm{mg} / \mathrm{dl})$ with $\mathrm{l}$ cell $/ \mu \mathrm{l}$. The patient was diagnosed as having "probable CIDP" because of the clinical and physiological findings, based on the criteria published by the American Academy of Neurology AIDS Task Force. ${ }^{1}$

Figure 1 shows each treatment and response. He underwent six sessions of PE (every other day) starting on 23 June 1998. His strength improved rapidly after the first PE, and after the sixth he could walk without support. His NIS decreased to 6 (right) and 5 (left). Steroid therapy consisting of a daily dose of $60 \mathrm{mg}(\mathrm{l} \mathrm{mg} / \mathrm{kg})$ of oral prednisolone was started on 1 July 1998. After 1 month the dose was reduced by $5 \mathrm{mg}$ every week. While the drug was being tapered off, on 20 October 1998, at a dose of $20 \mathrm{mg}$, limb weakness recurred.

Abbreviations: CIDP, chronic inflammatory demyelinating polyneuropathy; IVlg, intravenous immunoglobulin; NIS, neuropathy impairment score; $\mathrm{PE}$, plasma exchange 
Table 1 Nerve conduction study results

\begin{tabular}{|c|c|c|c|c|c|c|c|c|c|c|c|c|c|c|c|}
\hline & \multicolumn{3}{|l|}{ Median nerve } & \multicolumn{3}{|l|}{ Ulnar nerve } & \multicolumn{3}{|c|}{ Peroneal nerve } & \multicolumn{3}{|c|}{ Posterior tibial nerve } & \multicolumn{3}{|l|}{ Sural nerve } \\
\hline & Normal limit & Right & Left & Normal limit & Right & Left & Normal limit & Right & Left & Normal limit & Right & Left & Normal limit & Right & Left \\
\hline \multicolumn{16}{|l|}{ Motor nerve conduction study } \\
\hline Motor nerve conduction velocity $(\mathrm{m} / \mathrm{s})$ & $>48.0$ & 34.0 & 27.0 & $>48.0$ & 38.0 & 36.0 & $>39.0$ & 35.0 & 34.0 & $>38.0$ & 38.0 & 38.0 & & & \\
\hline Distal latency (ms) & $<4.5$ & 5.7 & 6.3 & $<3.5$ & 3.4 & 3.3 & $<6.2$ & 7.5 & 7.7 & $<5.6$ & 7.1 & 7.2 & & & \\
\hline Distal CMAP amplitude (mV) & $>4.4$ & 5.6 & 4.6 & $>4.6$ & 5.8 & 4.3 & $>1.2$ & 4.8 & 3.7 & $>5.8$ & 5.1 & 4.6 & & & \\
\hline P/D ratio of CMAP amplitude & & 0.88 & 0.89 & & 0.79 & 0.76 & & 0.78 & 0.76 & & 0.87 & 0.85 & & & \\
\hline$P / D$ ratio of $C M A P$ duration & & 1.11 & 1.07 & & 1.16 & 1.20 & & 1.21 & 1.11 & & 1.12 & 1.17 & & & \\
\hline Minimum F-wave latency (ms) & $<29.5$ & 46.7 & 51.0 & $<29.1$ & ND & ND & $<52.9$ & ND & ND & $<52.7$ & 73.5 & 76.0 & & & \\
\hline \multicolumn{16}{|l|}{ Sensory nerve conduction study } \\
\hline Sensory nerve conduction velocity $(\mathrm{m} / \mathrm{s})$ & $>44.0$ & 48.0 & 50.0 & $>42.0$ & 42.0 & 44.0 & & & & & & & $>40.0$ & 48.0 & 47.0 \\
\hline SNAP amplitude $(\mu \mathrm{V})$ & $>11.1$ & 28.4 & 29.8 & $>7.8$ & 17.1 & 25.1 & & & & & & & $>3.0$ & 16.0 & 10.2 \\
\hline
\end{tabular}

The amplitude and duration of the initial negative phase were measured for the CMAPs.

CMAP, compound muscle action potential; ND, not done; P/D, proximal versus distal; SNAP, sensory nerve action potential.

He underwent five sessions of PE again (every other day), and the dose of prednisolone was increased to $60 \mathrm{mg}$. Although the combination of PE and prednisolone reduced his limb weakness, he had another relapse four weeks after the last PE.

Since the patient did not respond to steroids, we tried cyclophosphamide pulse therapy. From 12 December onwards he received $1.8 \mathrm{~g}\left(1 \mathrm{~g} / \mathrm{m}^{2}\right)$ cyclophosphamide intravenously in accordance with the therapeutic regimen reported by Good et al. ${ }^{12}$ He remained relapse free for four months, but in April 1999 he experienced relapses again. We adjusted the cyclophosphamide dose, in increments of $25 \%$ according to the protocol, to achieve transient reduction of the white blood cell count to 1500-2000/ $\mu$ l. Although the dose was increased to $2.2 \mathrm{~g}\left(1.25 \mathrm{~g} / \mathrm{m}^{2}\right)$ and then to $2.8 \mathrm{~g}$ $\left(1.6 \mathrm{~g} / \mathrm{m}^{2}\right)$, he continued to have relapses in May and June. PE was frequently required to alleviate the symptoms.

In May 1999, we stopped cyclophosphamide and replaced it with ciclosporin. Initially, $300 \mathrm{mg}$ ( $5 \mathrm{mg} / \mathrm{kg}$ per day) of ciclosporin (Sandimmun, Sandoz, Basel, Switzerland) was given in two divided doses. From 12 June 1999 it was reduced to $250 \mathrm{mg}$, which corresponds to a serum concentration of between 150 and $200 \mathrm{ng} / \mathrm{ml}$. Because the maximal effect of ciclosporin occurs after several weeks of treatment, the patient was given $25 \mathrm{~g}(0.4 \mathrm{~g} / \mathrm{kg})$ human immunoglobulin (Kenketsu glovenin-I-Nichiyaku, Nihon Pharmaceutical, Tokyo, Japan) intravenously daily for five days from 18
June onwards. His strength greatly improved four days after the last infusion, and eight days later, he could walk unaided. On 1 July he again developed weakness. As he could not stand, another course of IVIg was given for five days, starting on 12 July. Again his strength improved, and in August he could walk more than $100 \mathrm{~m}$ without needing to rest. Although improved strength was maintained, he was given $25 \mathrm{~g}$ IVIg $(0.4 \mathrm{~g} / \mathrm{kg})$ daily for five days from 9 August onwards and $65 \mathrm{~g}(1 \mathrm{~g} / \mathrm{kg})$ human immunoglobulin each on 8 September and 6 October 1999.

In May 2000, his medication was switched from Sandimmun to Neoral (200 mg; Sandoz, Basel, Switzerland), a new formulation of ciclosporin based on a microemulsion drug delivery system. He had no further relapses for 27 months after the last treatment with IVIg. The dose of ciclosporin was slowly tapered and, on the patient's request, it was stopped on 30 January 2002. On 22 February hand weakness reappeared; $200 \mathrm{mg}$ daily of ciclosporin was started again and IVIg was given daily for five days from 6 March onwards. His grip strength improved rapidly. The strength of all four limbs gradually increased and by August 2002 all weakness disappeared. Since restarting ciclosporin there have been no further relapses, the patient's condition having been stable for 20 months. At the last follow up evaluation in April 2004, he had normal strength in all limbs. The motor nerve conduction velocities in both median, ulnar, and right tibial nerves had increased, and the compound muscle action

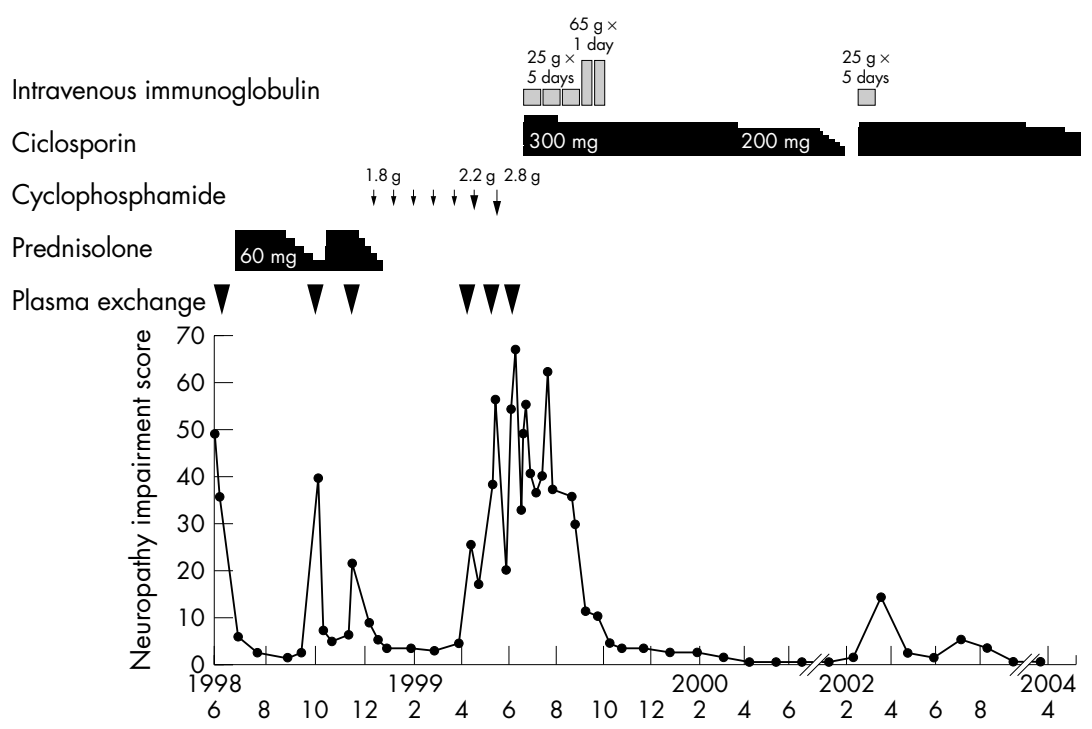

Figure 1 Clinical course: the patient did not respond to prednisolone and cyclophosphamide pulse therapies, but the neuropathy impairment score decreased (see right side of graph) during treatment with ciclosporin in combination with intravenous immunoglobulin. 
potential amplitude had increased in both the tibial nerves and the left ulnar nerve. He is still taking ciclosporin, $160 \mathrm{mg} /$ day, and the serum concentration is between 100 and $150 \mathrm{ng} /$ $\mathrm{ml}$. Except for hypertrichosis, there have been no side effects.

\section{THERAPEUTIC RESPONSES OF AND OUTCOMES FOR 15 CONSECUTIVE PATIENTS WITH CIDP}

Table 2 shows the therapeutic responses of and outcomes for 15 consecutive patients with CIDP, including the patient described above, who were treated with our proposed protocol as described below (fig 2). All patients were admitted to Dokkyo University School of Medicine Hospital between 1998 and 2003. All responded to IVIg or PE as the initial therapy, but four (patients 9-12) did not improve after being given steroids and a second line maintenance therapy was required.

Patient 9 did not respond to steroids and IVIg was frequently required. Subsequently, cyclophosphamide pulse therapy was given monthly for six months, but it was also unsuccessful. Ciclosporin was substituted for cyclophosphamide with no clear beneficial response. We considered using tacrolimus, and therapy was started with a daily dose of $3 \mathrm{mg}$. It had no beneficial effect and IVIg was given again.

Patient 10 had predominant motor dysfunction and responded rapidly to IVIg in combination with steroids, but relapse occurred while prednisolone was being tapered off. The steroid therefore was switched to ciclosporin. A second course of IVIg was given four weeks after the first, and the patient has been stable for nine months.

Patient 11 was given oral prednisolone after IVIg treatment. There was an initial response to prednisolone, but relapse occurred while it was being tapered off and diabetes mellitus developed. Although repeated IVIg produced transient improvement, relapse occurred again one month after the last IVIg. Treatment with ciclosporin was started, after which IVIg was no longer necessary. Since the introduction of ciclosporin there have been no further relapses, the patient's condition having been stable for 20 months.

Patient 12 had motor and sensory dysfunction, responded temporarily to IVIg, but limb weakness persisted. Despite treatment with prednisolone and PE, weakness remained. IVIg was given monthly for three months and ciclosporin started. The patient's strength gradually improved, and there have been no relapses for 18 months.

In all four patients there were no serious side effects of ciclosporin.

\section{DISCUSSION}

Our patient with CIDP did not respond to steroid and cyclophosphamide pulse therapies and was successfully treated with ciclosporin. Relapse after ciclosporin had been tapered off indicated that ciclosporin was effective and necessary as a maintenance therapy. The patient was young with selective motor involvement, no sensory symptoms or signs, and normal findings on sensory conduction studies. Four patients with a pure motor form of CIDP were reported by Sabatelli et al. ${ }^{13}$ Selective involvement of motor fibres was suggested by the absence of abnormal sensory symptoms or signs and normal findings in an electrophysiological study of sensory fibres and in a sural nerve biopsy. Sabatelli's patients had a younger age of onset (3-29 years), and the clinical course was relapsing-remitting. All four patients did not

Table 2 Responses of and outcomes for 15 CIDP patients after treatment with the proposed standardised protocol

\begin{tabular}{|c|c|c|c|c|c|c|c|c|c|}
\hline \multirow[b]{2}{*}{ Patient } & \multirow[b]{2}{*}{$\begin{array}{l}\text { Age at } \\
\text { onset/sex }\end{array}$} & \multirow[b]{2}{*}{$\begin{array}{l}\text { Initial therapy and } \\
\text { response }\end{array}$} & \multicolumn{4}{|l|}{ Maintenance therapies and responses } & \multirow[b]{2}{*}{ Outcomes* } & \multicolumn{2}{|c|}{ NIS (severe side) $\dagger$} \\
\hline & & & 1 & 2 & 3 & 4 & & $\begin{array}{l}\text { Before } \\
\text { treatment }\end{array}$ & $\begin{array}{l}\text { After } \\
\text { stabilisation } \\
\text { and remission }\end{array}$ \\
\hline \multirow[t]{2}{*}{$1 \neq$} & $34 / M$ & Plasma exchange & Oral prednisolone & Cyclophosphamide pulse & Ciclosporin & & Stabilised for 26 months & 51 & 0 \\
\hline & & Temporarily responded & $\begin{array}{l}\text { Temporarily responded, relapsed } \\
\text { during tapering }\end{array}$ & Unchanged & Responded & & & & \\
\hline \multirow[t]{2}{*}{2} & $47 / M$ & Plasma exchange & Oral prednisolone & No therapy required & & & Complete remission & 42 & 0 \\
\hline & & Temporarily responded & Responded & & & & (40 months) & & \\
\hline \multirow[t]{2}{*}{3} & $59 / \mathrm{F}$ & Plasma exchange & Oral prednisolone & No therapy required & & & Complete remission & 39 & 0 \\
\hline & & Temporarily responded & Responded & & & & (34 months) & & \\
\hline \multirow[t]{2}{*}{4} & $62 / M$ & Plasma exchange & Oral prednisolone & No therapy required & & & Complete remission & 67 & 0 \\
\hline & & Temporarily responded & Responded & & & & (32 months) & & \\
\hline \multirow[t]{2}{*}{5} & $46 / \mathrm{M}$ & IVlg & Oral prednisolone & No therapy required & & & Complete remission & 36 & 0 \\
\hline & & Rapidly responded & Responded & & & & (29 months) & & \\
\hline \multirow[t]{2}{*}{6} & $52 / M$ & IVlg & Oral prednisolone & No therapy required & & & Complete remission & 28 & 0 \\
\hline & & Rapidly responded & Responded & & & & (28 months) & & \\
\hline \multirow[t]{2}{*}{7} & $44 / \mathrm{F}$ & IVlg & Oral prednisolone & No therapy required & & & Complete remission & 46 & 0 \\
\hline & & Slowly responded & Responded & & & & (24 months) & & \\
\hline \multirow[t]{2}{*}{8} & $11 / \mathrm{M}$ & IVlg & Oral prednisolone & No therapy required & & & Complete remission & 30 & 0 \\
\hline & & Rapidly responded & Responded & & & & (18 months) & & \\
\hline \multirow[t]{2}{*}{9} & $53 / M$ & IVlg & Oral prednisolone & Cyclophosphamide pulse & Ciclosporin & Tacrolimus & Stabilised for 12 months; & 66 & 12 \\
\hline & & Temporarily responded & Unchanged, relapsed during tapering & Unchanged & Unchanged & Unchanged & maintained IVlg & & \\
\hline \multirow[t]{2}{*}{10} & $45 / \mathrm{F}$ & IVlg & Oral prednisolone & Ciclosporin & & & Stabilised for 9 months; & 37 & 6 \\
\hline & & Temporarily responded & $\begin{array}{l}\text { Temporarily responded, relapsed } \\
\text { during tapering }\end{array}$ & Responded & & & $\begin{array}{l}\text { maintained IVIg; no further } \\
\text { relapses }\end{array}$ & & \\
\hline \multirow[t]{2}{*}{11} & $34 / \mathrm{F}$ & IVlg & Oral prednisolone & Ciclosporin & & & Stabilised for 20 months; & 45 & 7 \\
\hline & & Temporarily responded & $\begin{array}{l}\text { Temporarily responded, relapsed } \\
\text { during tapering }\end{array}$ & Responded & & & $\begin{array}{l}\text { no IVlg required; no further } \\
\text { relapses }\end{array}$ & & \\
\hline \multirow[t]{2}{*}{12} & $65 / \mathrm{F}$ & IVlg & Oral prednisolone & Ciclosporin & & & Stabilised for 18 months; & 48 & 4 \\
\hline & & Temporarily responded & Unchanged, progressed & Responded & & & $\begin{array}{l}\text { no IVlg required; no further } \\
\text { relapses }\end{array}$ & & \\
\hline \multirow[t]{2}{*}{13} & $19 / \mathrm{F}$ & $\mathrm{IVlg}$ & Oral prednisolone & & & & Stabilised for 12 months; & 31 & 4 \\
\hline & & Rapidly responded & Responded & & & & no IVlg required & & \\
\hline \multirow[t]{2}{*}{14} & $45 / M$ & IVlg & Oral prednisolone & & & & Stabilised for 11 months; & 42 & 6 \\
\hline & & Rapidly responded & Responded & & & & no IVlg required & & \\
\hline \multirow[t]{2}{*}{15} & $37 / M$ & IVlg & Oral prednisolone & & & & Stabilised for 6 months; & 37 & 3 \\
\hline & & Rapidly responded & Responded & & & & no IVlg required & & \\
\hline
\end{tabular}

*Duration of remission since steroids were stopped.

†Neurological impairment score; previously called the neurological disability score (described by Dyck PJ et al'); sum score of maximum severity= 120 . ‡Patient in case report.

IVlg, intravenous immunoglobulin. 


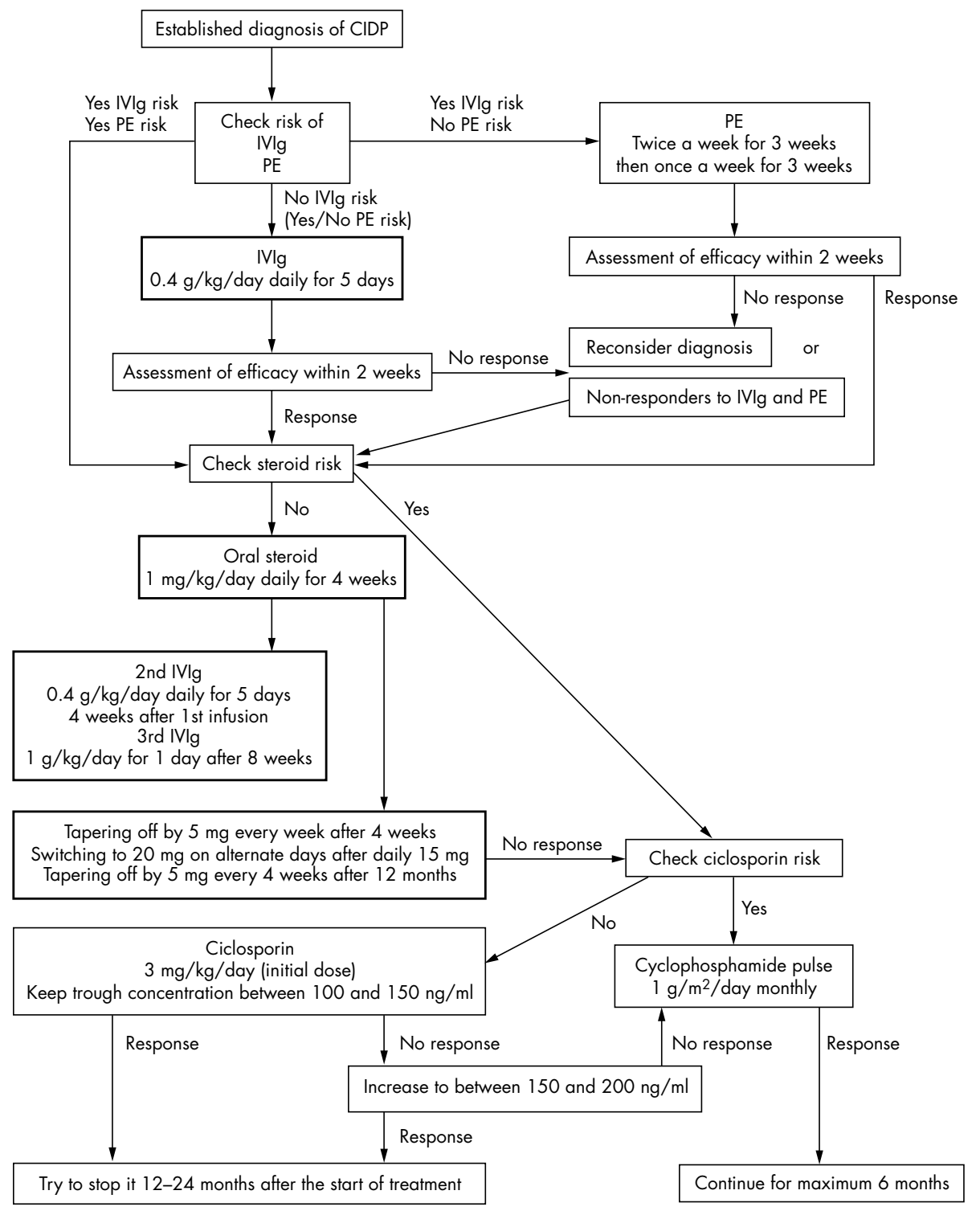

respond to steroids but showed considerable improvement with IVIg. Our patient's clinical features were similar to theirs. Ciclosporin should be considered for treatment resistant CIDP.

Successful treatment of CIDP with ciclosporin has been reported previously. ${ }^{9-11}$ Mahattanakul et al ${ }^{11}$ started ciclosporin at 3-5 mg/kg per day in eight patients, three of whom either improved or stopped taking prednisone. The authors reported that ciclosporin might prove an ideal long term treatment for young patients with relapsing CIDP, sparing them the side effects of steroids. Barnett et al investigated the role of ciclosporin in the treatment of 19 patients with resistant CIDP who had not responded adequately to steroids, PE, IVIg, and other immunosuppressive therapies. The patients were divided into progressive and relapsing types based on the course of the disease and their response to therapy at follow up as graded by clinical and electrophysiological criteria. That study strongly indicated that ciclosporin was an effective therapeutic agent for patients with both types of resistant CIDP. They could not, however, identify any clinical characteristics which would predict a response to ciclosporin therapy.

CIDP is considered to be an immune mediated disorder based on its positive responses to immunotherapy, although the pathomechanisms are unclear. Antibodies have long been suspected of mediating nerve damage in CIDP because most CIDP patients respond to PE. Antibodies to the P0 myelin glycoprotein have been reported, which are capable of inducing experimental demyelination. ${ }^{14}$ In contrast, endoneurial inflammatory changes due to $\mathrm{T}$ cell infiltration and macrophage associated demyelination during the active phase are often seen in nerve biopsy specimens. ${ }^{15} 16$ Ciclosporin acts by inhibiting $\mathrm{T}$ cell dependent immune responses ${ }^{17}{ }^{18}$ and produces its immunosuppressant effects by inhibiting calcineurin mediated dephosphorylation of the nuclear factor of activated $\mathrm{T}$ cells bound to cyclophilin. Although pathomechanisms in CIDP are not clear, it may suppress responses of helper $\mathrm{T}$ cells by inhibiting the production of interleukin- 2 and interferon- $\gamma$ and preventing further recruitment and activation of macrophages. 


\section{PROVISIONAL TREATMENT PROTOCOL}

On the basis of evidence from randomised controlled trials ${ }^{2-81920}$ and our own clinical experience, we have established a treatment protocol for CIDP (see fig 2). A randomised crossover study comparing IVIg with PE showed they were equally effective for treating CIDP. ${ }^{19}$ A recent randomised crossover trial compared IVIg with oral prednisolone. ${ }^{20}$ The outcome measure showed slight but not significantly more improvement with IVIg than with prednisolone. The duration of treatment, however, was relatively short for a chronic disorder that generally requires treatment for many months or years. Steroid therapy is inexpensive and readily available, but its benefits take as long as two months to appear. ${ }^{20} 21$ In contrast, IVIg and PE provide rapid stabilisation and improvement, often within the first week of therapy.

In the treatment of CIDP, a distinction needs to be made between initial and maintenance therapy. Except in the presence of IgA deficiency, renal failure, and vascular disease or cardiac insufficiency complications, IVIg is generally well tolerated and easy to administer; therefore, IVIg rather than PE should be the initial therapy. For patients at risk with IVIg, PE is the preferred initial therapy. For those patients with illnesses of undetermined diagnosis, a trial IVIg or PE can resolve the nature of the immune-mediated disorder. A treatment algorithm for CIDP based on systematic review has been proposed. ${ }^{22}$ It is recommend that patients with mild to moderate impairment and disability who do not have a pure motor form of CIDP or contraindication to steroid therapy should be started on prednisolone. Patients with moderate to severe impairment and disability in whom a quick response is needed or those with pure motor forms should be treated with IVIg. Most patients with CIDP improve after treatment with IVIg, but many experience relapses and require periodic administration of IVIg at intervals of several weeks to maintain improvement. The length of IVIg treatment needed is not yet clear. To decrease the frequency of IVIg administration, a trial of oral immunosuppressants should be offered to patients who have relapses. ${ }^{5}$

For maintenance therapy, steroids should be started in conjunction with IVIg or PE. Because the maximal effect of steroids may be delayed for two months or more after start of therapy, ${ }^{20}$ additional IVIg courses should be provided. Second $(0.4 \mathrm{~g} / \mathrm{kg}$ per day daily for five days) and third ( $1 \mathrm{~g} /$ $\mathrm{kg}$ per day for one day) IVIg courses, respectively, have been given four and eight weeks after the first infusion. Because treatment for less than six months and rapid tapering of steroids may increase risk of relapse, ${ }^{23}$ the steroid dose is slowly reduced over a 12 month period. There have been anecdotal reports of beneficial treatment with cyclophosphamide, ciclosporin, and mycophenolate but no randomised trials. ${ }^{24}$ Based on our clinical experience, if patients have relapses after steroid reduction and require repeated IVIg or PE, ciclosporin should be considered. Published data on ciclosporin are limited to several small case series, and the response rates range from $40 \%$ to $90 \% .{ }^{9}{ }^{11}$ If patients respond to treatment with ciclosporin, improvement generally starts after two months. ${ }^{25}$ However, it has potential side effects such as nephrotoxicity, hypertension, nausea, oedema, hirsutism, headaches, and cramps, so patients with pre-existing severe renal impairment and hypertension should not be given ciclosporin. Nephrotoxicity, the most frequent side effect of ciclosporin, is usually dose dependent. It occurred in three of eight patients who began ciclosporin therapy on the high dose of $7 \mathrm{mg} / \mathrm{kg}$ per day or more and this necessitated reduction or cessation of the drug..$^{9}$ Ciclosporin therapy can be made safe and effective by starting with a dose of $3 \mathrm{mg} / \mathrm{kg}$ and by close clinical monitoring of the patient's serum ciclosporin and creatinine concentrations. Based on our experiences, serum trough concentrations should be kept between 100 and $150 \mathrm{ng} / \mathrm{ml}$ during the first six months of treatment. Patients who fail to respond to IVIg, PE, steroids, and ciclosporin may require other potentially effective immunotherapy such as cyclophosphamide, ${ }^{12}$ tacrolimus, ${ }^{26}$ interferon alfa ${ }^{27}$ and beta, ${ }^{28}$ mycophenolate, ${ }^{29}$ or autologous stem cell transplantation. ${ }^{30}$

CIDP is a heterogeneous disorder and clinical course and response to treatment varies. ${ }^{31}$ Also, there are several variants of the disease. ${ }^{32-36}$ Whether each variant requires a specific treatment is not clear. Because it is impossible to predict in advance who will respond to which treatment, we use the standard therapeutic protocol to treat all patients with CIDP. The favorable findings in our patients, as well as those in previous reports, ${ }^{911}$ support the need for a randomised controlled trial of ciclosporin for the treatment of CIDP. The beneficial effects of maintenance IVIg pulse therapy, reported by Hahn et al, ${ }^{5}$ also require confirmation by long term trials. Larger studies may determine which subgroups of patients will respond to a particular therapeutic regimen.

\section{ACKNOWLEDGEMENT}

We thank Dr M Koga (Department of Neurology, Dokkyo University School of Medicine, Tochigi) for his critical reading of this paper.

\section{Authors' affiliations}

M Odaka, M Tatsumoto, K Susuki, K Hirata, N Yuki, Department of Neurology, Dokkyo University School of Medicine, Shimotsuga, Tochigi, Japan

Competing interests: none declared

Patient consent was obtained.

\section{REFERENCES}

1 Report from an Ad Hoc Subcommittee of the American Academy of Neurology AIDS Task Force. Research criteria for diagnosis of chronic inflammatory demyelinating polyneuropathy (CIDP). Neurology 1991:41:617-18.

2 Dyck PJ, O'Brien PC, Oviatt KF, et al. Prednisone improves chronic inflammatory demyelinating polyradiculoneuropathy more than no treatment. Ann Neurol 1982;11:136-41.

3 Dyck PJ, Daube J, O'Brien $\mathrm{P}$, et al. Plasma exchange in chronic inflammatory demyelinating polyradiculoneuropathy. N Engl J Med 1986;314:461-5.

4 Hahn AF, Bolton CF, Pillay N, et al. Plasma-exchange therapy in chronic inflammatory demyelinating polyneuropathy: a double-blind, shamcontrolled, cross-over study. Brain 1996;119:1055-66.

5 Hahn AF, Bolton CF, Zochodne D, et al. Intravenous immunoglobulin treatment in chronic inflammatory demyelinating polyneuropathy: a double-blind, placebo-controlled, cross-over study. Brain 1996;119:1067-77.

6 Mendell JR, Barohn RJ, Freimer ML, et al. Randomized controlled trial of IVlg in untreated chronic inflammatory demyelinating polyradiculoneuropathy. Neurology 2001;56:445-9.

7 Thompson N, Choudhary P, Hughes RA, et al. A novel trial design to study the effect of intravenous immunoglobulin in chronic inflammatory demyelinating polyradiculoneuropathy. J Neurol 1996;243:280-5.

8 van Doorn PA, Brand A, Strengers PFW, et al. High-dose intravenous immunoglobulin treatment in chronic inflammatory demyelinating polyneuropathy: a double-blind, placebo-controlled, crossover study. Neurology 1990:40:209-12.

9 Barnett MH, Pollard JD, Davies L, et al. Cyclosporin A in resistant chronic inflammatory demyelinating polyradiculoneuropathy. Muscle Nerve 1998;21:454-60.

10 Hefter H, Sprenger KB, Arendt G, et al. Treatment of chronic relapsing inflammatory demyelinating polyneuropathy by cyclosporin $A$ and plasma exchange: a case report. $J$ Neurol 1990;237:320-3.

11 Mahattanakul W, Crawford TO, Griffin JW, et al. Treatment of chronic inflammatory demyelinating polyneuropathy with cyclosporin-A. J Neurol Neurosurg Psychiatry 1996;60:185-7.

12 Good JL, Chehrenama M, Mayer RF, et al. Pulse cyclophosphamide therapy in chronic inflammatory demyelinating polyneuropathy. Neurology 1998;51:1735-8.

13 Sabatelli M, Madia F, Mignogna T, et al. Pure motor chronic inflammatory demyelinating polyneuropathy. J Neurol $2001 ; 248: 772-7$.

14 Yan WX, Archelos JJ, Hartung H-P, et al. PO protein is a target antigen in chronic inflammatory demyelinating polyradiculoneuropathy. Ann Neurol 2001;50:286-92

15 Bosboom WMJ, van den Berg LH, de Boer L, et al. The diagnostic value of sural nerve T cells in chronic inflammatory demyelinating polyneuropathy. Neurology 1999;53:837-45 
16 Schmidt B, Toyka KV, Kiefer R, et al. Inflammatory infiltrates in sural nerve biopsies in Guillain-Barré syndrome and chronic inflammatory demyelinating neuropathy. Muscle Nerve 1996;19:474-87.

17 Hess AD, Tutschka PJ. Effect of cyclosporin A on human lymphocyte response in vitro. I. CsA allows for the expression of alloantigen-activated suppressor cells while preferentially inhibiting the induction of cytolytic effector lymphocytes in MLR. J Immunol 1980;124:2601-8.

18 Ho S, Clipstone N, Timmermann L, et al. The mechanism of action of cyclosporin A and FK506. Clin Immunol Immunopathol 1996;80(suppl):40-5.

19 Dyck PJ, Litchy WJ, Kratz KM, et al. A plasma exchange versus immune globulin infusion trial in chronic inflammatory demyelinating polyradiculoneuropathy. Ann Neurol 1994;36:838-45.

20 Hughes $\mathrm{R}$, Bensa S, Willison $\mathrm{H}$, et al. Randomized controlled trial of intravenous immunoglobulin versus oral prednisolone in chronic inflammatory demyelinating polyneuropathy. Ann Neurol 2001;50:195-201.

21 Saxon A, Stevens RH, Ramer SJ, et al. Glucocorticoids administered in vivo inhibit human suppressor T lymphocyte function and diminish B lymphocyte responsiveness in in vitro immunoglobulin synthesis. J Clin Invest 1978;61:922-30.

22 van Schaik IN, Winer JB, de Haan R, et al. Intravenous immunoglobulin for chronic inflammatory demyelinating polyradiculoneuropathy: a systematic review. Lancet Neurol 2002;1:491-8.

23 Wertman E, Argov Z, Abrmasky O. Chronic inflammatory demyelinating polyradiculoneuropathy: features and prognostic factors with corticosteroid therapy. Eur Neurol 1988;28:199-204.

24 Hughes RA, Swan AV, van Doorn PA. Cytotoxic drugs and interferons for chronic inflammatory demyelinating polyradiculoneuropathy. Cochrane Database Syst Rev 2003;1:CD003280.

25 Kahan BD. Cyclosporin. N Engl J Med 1989;321:1725-36.
26 Ahlmén J, Andersen $\mathrm{O}$, Hallgren $\mathrm{G}$, et al. Positive effects of tacrolimus in a case of CIDP. Transplant Proc 1998;30:4194.

27 Gorson KC, Ropper AH, Clark BD, et al. Treatment of chronic inflammatory demyelinating polyneuropathy with interferon- $\alpha 2 a$. Neurology 1998:50:84-7.

28 Hadden RDM, Sharrack B, Bensa S, et al. Randomized trial of interferon betala in chronic inflammatory demyelinating polyradiculoneuropathy. Neurology 1999;53:57-61.

29 Mowzoon N, Sussman A, Bradley WG. Mycophenolate (CellCept) treatment of myasthenia gravis, chronic inflammatory polyneuropathy and inclusion body myositis. J Neurol Sci 2001;185:119-22.

30 Vermeulen $M$, van Oers $M H$. Successful autologous stem cell transplantation in a patient with chronic inflammatory demyelinating polyneuropathy. J Neurol Neurosurg Psychiatry 2002;72:127-8.

31 Saperstein DS, Katz JS, Amato AA, et al. Clinical spectrum of chronic acquired demyelinating polyneuropathy. Muscle Nerve 2001;24:311-24.

32 van den Berg-Vos RM, van den Berg LH, Franssen H, et al. Multifocal inflammatory demyelinating neuropathy: a distinct clinical entity? Neurology 2000:54:26-32.

33 Saperstein DS, Amato AA, Wolfe GI, et al. Multifocal acquired demyelinating sensory and motor neuropathy: the Lewis-Sumner syndrome. Muscle Nerve 1999;22:560-6.

34 Katz JS, Saperstein DS, Gronseth G, et al. Distal acquired demyelinating symmetric neuropathy. Neurology 2000;54:615-20.

35 Uncini A, Sabatelli M, Mignogna T, et al. Chronic progressive steroid responsive axonal polyneuropathy: a CIDP variant or a primary axonal disorder? Muscle Nerve 1996;19:365-71.

36 Oh SJ, Joy JL, Kuruoglu R. "Chronic sensory demyelinating neuropathy": chronic inflammatory demyelinating polyneuropathy presenting as a pure sensory neuropathy. J Neurol Neurosurg Psychiatry 1992;55:677-80. 